\title{
MODEL ADOPSI PRODUK BANK SYARI'AH DI KUDUS: PENGEMBANGAN THEORY OF REASONED ACTION DAN SYARIAH COMPLIANCE
}

\author{
Anita Rahmawaty \\ Sekolab Tinggi Agama Islam Negeri (STAIN) Kudus \\ ita_rabma@yaboo.co.id
}

\begin{abstract}
This study aims to analyze adoption model of Islamic bank products based on Theory of Reasoned Action (TRA) on the societies in Kudus. This study is a type of survey research by using a quantitative approach. The research data are obtained from 140 respondents by using convenience sampling technique. For research model testing technique, it used the statistical test Discriminant Analysis. The findings of this study is shown that the value of $0.753 C R^{2}$. If this value is squared $(0,753)^{2}=0,567$, meaning that all discriminant variables (subjective norm, attitude towards use, syariah compliance and trust) can explain the differences in people's behavior towards Islamic bank products between the customers of Islamic bank (adopter) and non-customers (non-adopter) by 56, 7\%. While the adoption rate of product acceptance in the Islamic bank can be predicted with four predictor variables with the classification level of $95.7 \%$ with two levels of adoption of Islamic bank products (adopters and non-adopters).
\end{abstract}

Keywords: Theory of Reasoned Action (TRA), Syariah Compliance, Trust.

\begin{abstract}
Abstrak
Penelitian ini bertujuan untuk menganalisis model adopsi produk bank syari'ah pada masyarakat di Kabupaten Kudus. Penelitian ini merupakan jenis penelitian survey dengan menggunakan pendekatan kuantitatif. Data penelitian ini diperoleh dari 140 responden, dengan menggunakan teknik convenience sampling. Teknik pengujian model penelitian ini menggunakan uji statistik Discriminant Analysis. Temuan penelitian ini menunjukkan bahwa nilai $C R^{2}$ sebesar 0, 753. Jika nilai ini dikuadratkan $(0.753)^{2}=0.567$, artinya babwa selurub variabel diskriminan (subjective norm, attitude towards use, syariab compliance dan trust) mampu menjelaskan perbedaan perilaku masyarakat terbadap produk bank syari'ab antara nasabah bank syari'ab dan non nasabah sebesar 56, 7\%. Sedangkan tingkat adopsi penerimaan produk bank syari'ab pada masyarakat Kudus dapat diprediksi dengan empat variabel prediktor dengan tingkat klasifikasi sebesar $95.7 \%$ dengan dua tingkat adopsi produk banksyari'ab (nasabab/adopter dan non-nasabab/non-adopter).
\end{abstract}

Kata Kunci: Theory of Reasoned Action (TRA), Kepatuhan Syariah, Kepercayaan 


\section{Pendahuluan}

Pertumbuhan industri perbankan Syari'ah di Indonesia menunjukkan trend yang terus meningkat semakin pesat, setelah mengalami perlambatan pertumbuhan akibat terimbas krisis Amerika Serikat tahun 2008/2009. Pada akhir September 2011, pertumbuhan aset mencapai 47.8\% atau Rp. 123.4 triliun, tertinggi sejak tahun 2005. Pertumbuhan dana pihak ketiga (DPK) dan pembiayaan yang diberikan (PYD) pada waktu yang sama bahkan lebih pesat lagi, masing-masing mencapai 53\% atau Rp. 97.8 triliun dan 52.3\% atau Rp. 92.8 triliun, dengan FDR (financing to deposits ratio) 95.7\%. Sebagai perbandingan, pertumbuhan aset perbankan konvensional pada waktu yang sama mencapai $22.2 \%$ atau Rp. 3371.5 triliun, dengan LDR (loan to deposits ratio) $81.4 \%$.

Kinerja perbankan Syari'ah dilihat dari BOPO (biaya operasi dibagi pendapatan operasi), ROA (return on assets) dan NPF (nonperforming financing) juga menunjukkan peningkatan. Pada akhir September 2011, BOPO, ROA, dan NPF masing-masing mencapai $77.5 \%, 1.8 \%$ dan 2\%. Sementara itu, CAR (capital adecuacy ratio) berada pada posisi yang aman 15.3\%. Sedangkan ROE (return on equity) mengalami penurunan ke $17.1 \%$. Secara umum, kinerja perbankan Syari'ah tersebut masih lebih baik dari kinerja perbankan konvensional, kecuali untuk ROA dan ROE karena masih pesatnya ekspansi (Ismail, Ascarya dan Sakti, 2012: 1).

Di samping itu, perkembangan perbankan syari'ah di Indonesia cukup pesat. Dalam kurun waktu 20 tahun, perbankan syari'ah secara keseluruhan terdiri dari 11 Bank Umum Syari'ah, 24 Unit Usaha Syari'ah dan 156 BPRS. Penambahan kuantitas perbankan syari'ah tersebut, tetap diimbangi dengan peningkatan kinerjanya. Pola pembiayaan tetap didominasi trade based financing, dengan target utama pembiayaan masih SMEs dan diperkirakan, secara moderat perbankan syari'ah nasional akan tumbuh 36\% pada tahun 2012 (Ismail, Ascarya dan Sakti, 2012: 3). 
Tabel 1. Perkembangan Bank Syari'ah di Indonesia

\begin{tabular}{lccccccc}
\hline \multicolumn{1}{c}{ URAIAN } & $\mathbf{2 0 0 6}$ & $\mathbf{2 0 0 7}$ & $\mathbf{2 0 0 8}$ & $\mathbf{2 0 0 9}$ & $\mathbf{2 0 1 0}$ & $\mathbf{2 0 1 1}$ & $\mathbf{2 0 1 2}$ \\
\hline Bank Umum Syariah & & & & & & & \\
$\begin{array}{l}\text { - Jumlah Bank } \\
\text { - Jumlah Kantor }\end{array}$ & 3 & 3 & 5 & 6 & 11 & 11 & 11 \\
$\begin{array}{l}\text { Unit Usaha Syari'ah } \\
\text {-Jumlah BU Konven. }\end{array}$ & 20 & 401 & 581 & 711 & 1.215 & 1.401 & 1.499 \\
$\begin{array}{l}\text { yang memiliki UUS } \\
\text { - Jumlah Kantor }\end{array}$ & 183 & 196 & 241 & 287 & 262 & 336 & 447 \\
$\begin{array}{l}\text { BPRS } \\
\text { - Jumlah Bank }\end{array}$ & 105 & 114 & 131 & 138 & 150 & 155 & 156 \\
- Jumlah Kantor & 105 & 185 & 202 & 225 & 286 & 364 & 377 \\
Total Kantor & $\mathbf{6 3 7}$ & $\mathbf{7 8 2}$ & $\mathbf{1 . 0 2 4}$ & $\mathbf{1 . 2 2 3}$ & $\mathbf{1 . 7 6 3}$ & $\mathbf{2 . 1 0 1}$ & $\mathbf{2 . 3 2 3}$ \\
\hline
\end{tabular}

Sumber: Statistik Perbankan Syariah, Mei 2012.

Mencermati pertumbuhan bank syari'ah tersebut, sekilas memang cukup membanggakan. Namun jika dilihat secara lebih mendalam, dengan memperhitungkan berbagai dimensi yang membentuk kinerja perbankan secara keseluruhan, baik dalam jangka pendek maupun jangka panjang, dimana bank konvensional lebih dahulu memikat hati masyarakat, sehingga lebih kuat struktur permodalannya, market share-nya lebih luas dan sebagai pengendali pasar (market leader), maka eksistensi bank syari'ah akan sulit terbebas dari posisi resistensi.

Salah satu faktor penting yang mempengaruhi perilaku konsumen untuk membeli atau memanfaatkan suatu produk adalah sikap. Ada kecenderungan bahwa sikap sebagai faktor yang paling kuat untuk memprediksi perilaku di masa mendatang. Sikap merupakan pengorganisasian proses persepsi, kognisi, emosi dan kecenderungan untuk bertindak. Salah satu teori yang bisa menjelaskan hubungan sikap, minat dan perilaku adalah Theory of Reasoned Action (TRA). TRA adalah teori yang menganalisis perilaku seseorang yang sangat tergantung pada minatnya, sedangkan minat untuk berperilaku sangat tergantung pada sikap dan norma subyektif pengguna.

Sikap terbentuk jika konsumen memiliki sikap positif atau negatif terhadap suatu produk. Semakin banyak segi positif/keuntungan yang diperoleh konsumen, maka semakin besar kemungkinan konsumen untuk membeli/menggunakan suatu produk. Sedangkan 
norma subyektif merupakan komponen yang berisikan keputusan yang dibuat seseorang setelah mempertimbangkan pandangan orang lain. Norma subyektif seseorang dipengaruhi oleh motivasi yang diperoleh dari keyakinan terhadap pendapat tersebut (Saragih, 2010: 363).

Berdasarkan studi terdahulu yang dilakukan oleh Bank Indonesia dan Undip tentang potensi, preferensi dan perilaku masyarakat terhadap bank syari'ah di Jawa Tengah dan Daerah Istimewa Yogyakarta (2000: 26) disimpulkan bahwa potensi nilai sosial (respon masyarakat terhadap hal-hal baru) Kabupaten Kudus adalah kurang responsif, potensi ekonomi yang menunjukkan tentang aksesibilitas wilayah serta tingkat pengeluaran keluarga, Kudus termasuk dalam kategori rendah, sedangkan potensi sistem sosial yang mencerminkan derajat keaktifan sosial menunjukkan Kudus merupakan daerah yang sangat tertutup.

Mencermati studi terdahulu di atas, sekilas memang Kabupaten Kudus dianggap kurang potensial untuk pengembangan ekonomi Islam dan perbankan syari'ah. Namun demikian, mengingat mayoritas penduduk Kabupaten Kudus adalah beragama Islam. Di samping itu, secara kultur, Kudus dipandang sebagai kota yang religius karena kota Kudus merupakan salah satu daerah pantura yang memiliki banyak pesantren di wilayah sekitar masjid menara Kudus, maka perlu dilakukan penelitian lanjutan mengenai perbedaan perilaku masyarakat terhadap bank syari'ah di Kabupaten Kudus.

Berdasarkan survei penulis, persepsi dan sikap masyarakat Kudus terhadap bank syari'ah, ternyata sangat beragam. Sebagian masyarakat, ada yang sudah benar-benar memahami apa itu bank syari'ah, fungsi dan perannya dalam perekonomian serta produkproduk operasionalnya sehingga bersikap positif terhadap bank syari'ah. Namun, ada sebagian masyarakat yang bersikap mendua untuk menerima bank syari'ah sekaligus bank konvensional, bahkan ada sebagian masyarakat yang bersikap negatif terhadap bank syari'ah, sehingga hanya menggunakan produk jasa bank konvensional saja.

Melihat potret fenomena tersebut di atas, dapat ditarik kesimpulan bahwa terdapat kesenjangan minat dan perilaku masyarakat Kudus dalam berafiliasi antara bank konvensional dengan bank 
syari'ah, mengingat mayoritas masyarakat Kudus adalah beragama Islam. Namun, persepsi dan preferensi masyarakat Kudus terhadap bank syari'ah cukup bervariasi, meskipun bank syari'ah dalam filosofinya lebih mengedepankan kepentingan masyarakat sebagai rablmatan lil 'a $>>$ lami $>n$.

Beberapa penelitian terdahulu yang terkait dengan sikap, minat dan perilaku konsumen yang menggunakan pendekatan model TRA, di antaranya adalah Saragih (2010: 362) menerapkan model TRA untuk memprediksi minat perilaku pembelian sepeda motor Yamaha Mio di Medan. Hasil penelitiannya menunjukkan bahwa minat perilaku pembelian sepeda motor mio dipengaruhi oleh variabel sikap dan norma subyektif. Namun demikian, sikap masyarakat Medan lebih dominan mempengaruhi minat perilaku pembelian. Studi Lavindri dan Kurnia (2012: 1) mengkombinasikan 4 (empat) teori penerimaan teknologi informasi, yaitu TRA, TPB, TAM dan IDT dalam pengadopsian Twitter Advertising di Jabotabek. Hasil penelitiannya menunjukkan bahwa sikap, norma subyektif dan persepsi manfaat berpengaruh signifikan terhadap minat pengadopsian Twitter Advertising.

Sementara itu, Wahyudi (2011: 1) menunjukkan dalam penelitiannya bahwa perceived expressiveness, perceived enjoyment, perceived ease of use, perceived usefulness dan subjective norm berpengaruh signifikan terhadap minat menggunakan mini laptop. Winarto (2008: 51) dalam studinya menunjukkan bahwa sikap memiliki pengaruh yang signifikan terhadap minat memilih kuliah di Universitas Hang Tuah Surabaya, sedangkan keinginan, norma subyektif dan persepsi kontrol keperilakuan tidak berpengaruh secara signifikan.

Sedangkan penelitian terdahulu terkait dengan perilaku masyarakat terhadap bank syari'ah, di antaranya adalah penelitian Bank Indonesia dan Universitas Brawijaya (2000: 5-20) membagi tiga faktor yang mempengaruhi bank custumer's decision process yaitu: (1) Marketing Stimuli (product, price, promotion dan place); (2) Other Stimuli (economy); dan (3) bank custumer's characteristics (culture, social, personal, psychological). Sedangkan hasil dari uji Logistic Regression menunjukan bahwa faktor-faktor yang mempengaruhi masyarakat individu untuk memilih bank syari'ah antara lain adalah: (1) payment periode; (2) warranties; (3) location; 
(4) economic circumstances; (5) role and status; (6) age and life cycle stages; (7) family dan (8) pendidikan

Berbeda dengan penelitian terdahulu di atas, penelitian ini menguji 4 (empat) variabel prediktor, yaitu subjective norm, attitude towards use, syariah compliance dan trust, yang bersumber dari model Theory of Reasoned Action (TRA), dengan penambahan variabel, yaitu syariah compliance dan trust. Selain itu, tingkat adopsi bank syari'ah diukur dengan menggunakan 2 (dua) skala, yaitu nasabah (adopter) dan non nasabah (non adopter).

Theory of Reasoned Action (TRA)

Theory of Reasoned Action (TRA) pertama kali dicetuskan oleh Fishbein dan Ajzen pada tahun 1975. Sebenarnya teori ini berasal dari salah satu model perilaku psikologi sosial. Teori ini menjelaskan bahwa perilaku (behavior) seseorang itu dilakukan karena seseorang memiliki minat atau keinginan untuk melakukannya (behavioral intention) atau dengan kata lain minat perilaku akan menentukan perilakunya (Vallerand dan Pelletier, 1992: 983).

TRA mengusulkan bahwa minat perilaku adalah suatu fungsi dari sikap (attitude) dan norma-norma subjektif (subjective norm). Dalam upaya mengungkapkan pengaruh sikap (attitude) dan norma-norma subjektif (subjective norm) terhadap minat perilaku, Fishbein dan Ajzen melengkapi model TRA ini dengan keyakinan (belief). Dikemukakannya bahwa sikap berasal dari keyakinan terhadap perilaku (behavioral belief), sedangkan norma subjektif berasal dari keyakinan normatif (normative belief) (Davis, Bagozzi dan Warshaw, 1989: 984). Secara skematik model TRA dapat digambarkan sebagai berikut:

Gambar 1. Theory of Reasoned Action (TRA)

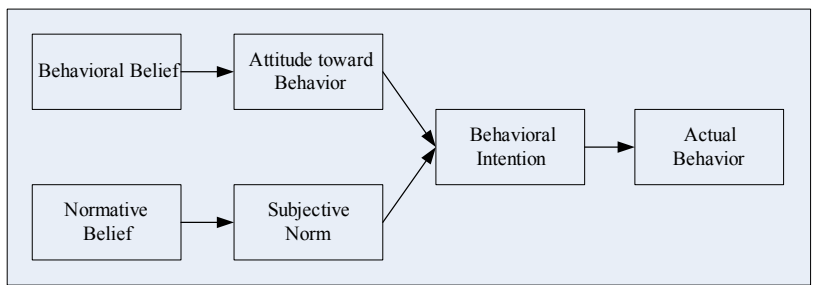

Sumber: Davis, Bagozzi dan Warshaw (1989: 984) 
Berdasarkan gambar di atas, maka komponen-komponen model Theory of Reasoned Action dapat dijelaskan sebagai berikut:

a. Sikap Konsumen

Secara historis, istilah sikap (attitude) digunakan pertama kali oleh Herbert Spencer pada tahun 1862 yang diartikan sebagai status mental seseorang. Sikap didefinisikan oleh Peter dan Olson sebagaimana dikemukakan oleh Saragih (2010: 365) sebagai suatu bentuk evaluasi atau reaksi perasaan. Sikap seseorang terhadap suatu objek adalah perasaaan mendukung maupun tidak mendukung pada objek tersebut. Secara sepesifik, sikap diformulasikan sebagai derajat efek positif atau efek negatif terhadap suatu objek psikologis. Sedangkan Boyd, dkk dalam Saragih (2010: 365) menjelaskan bahwa sikap bahwa perasaan positif atau negatif tentang suatu objek yang mempengaruhi seseorang untuk berperilaku dalam cara tertentu terhadap objek itu.

Sikap konsumen dapat diukur dari keyakinan terhadap atribut yang berisikan aspek pengetahuan tentang perilaku tertentu. Kalau dikaitkan dengan perilaku membeli/menggunakan, maka komponen ini selain berisikan pengetahuan tentang sikap membeli/menggunakan, komponen ini juga berisikan pengetahuan tentang konsekuensi positif atau negatif yang dapat diperoleh. Keyakinan tersebut dapat muncul dari dua sumber, yaitu keyakinan yang muncul dari adanya informasi tentang objek yang diperoleh dari berbagai sumber informasi, seperti surat kabar, majalah, brosur, iklan, dan lain-lain dan keyakinan terhadap berbagai aspek dari suatu objek sikap (Saragih, 2010: 365).

b. Norma Subjektif

Norma subjektif dipengaruhi oleh kelompok preferen dan motivasi dari orang lain. Segala sesuatu mengandung nilai, jika bagi seseorang tidak, mungkin bagi orang lain. Berdasarkan anggapan ini, seseorang melakukan sesuatu karena pertimbangan kebutuhan, moral atau kesadaran etik dan pertimbangan logika. Oleh karena itu, norma subjektif dipengaruhi oleh kayakinan normatif dan motivasi kelompok preferen. Keyakinan normatif adalah gagasan yang diterima oleh kelompok referen yang berpendapat bahwa sebaiknya atau tidak sebaiknya untuk mem- 
beli suatu produk. Pandangan orang lain dalam penelitian ini adalah pandangan keluarga, teman, orang yang dikenal dan masyarakat. Sedangkan motivasi adalah dorongan yang kuat untuk menuruti pengaruh kelompok referen untuk membeli suatu produk (Saragih, 2010: 366-367).

c. Minat Perilaku

Minat perilaku, menurut Reid dan Levy (2008: 18) adalah kecenderungan perilaku untuk tetap menggunakan suatu produk. Sutisna dalam Saragih (2010: 367) mendefinisikan minat sebagai kecenderungan memberikan tanggapan pada suatu objek atau kelompok objek, baik disenangi atau tidak disenangi secara konsisten. Dengan demikian, seseorang yang berminat terhadap suatu objek tertentu cenderung menaruh perhatian lebih besar terhadap objek tertentu tersebut. Sedangkan beberapa indikator minat perilaku, di antaranya adalah intend to use in the future, dan use on a regular basis dan recommend others to use (Reid dan Levy, 2008: 18).

Penelitian sebelumnya telah dilakukan oleh antara lain; Saragih (2010: 362) menerapkan model TRA untuk memprediksi minat perilaku pembelian sepeda motor Yamaha Mio di Medan. Hasil penelitiannya menunjukkan bahwa minat perilaku pembelian sepeda motor mio dipengaruhi oleh variabel sikap dan norma subyektif. Namun demikian, sikap masyarakat Medan lebih dominan mempengaruhi minat perilaku pembelian. Lavindri dan Kurnia (2012: 1) dalam studinya mengkombinasikan 4 teori penerimaan teknologi informasi, yaitu TRA, TPB, TAM dan IDT dalam pengadopsian Twitter Advertising di Jabotabek. Hasil penelitiannya menunjukkan bahwa sikap, norma subyektif dan persepsi manfaat berpengaruh signifikan terhadap minat pengadopsian Twitter Advertising.

\section{Syariab Compliance (Kepatuban terhadap syari'ah)}

Compliance didefinisikan oleh Othman dan Owen sebagai "the ability to fulfill with Islamic law and operate under the principles of Islamic banking and economy". Pendapat di atas berpandangan bahwa kepatuhan adalah kemampuan untuk memenuhi hukum Islam 
dan beroperasi di bawah prinsip-prinsip ekonomi dan perbankan syari'ah. Othman dan Owen menambahkan unsur compliance pada dimensi mutu pelayanan yang diteliti sebelumnya oleh Parasuraman, yang biasa dikenal dengan Compliance with Islamic lawkepatuhan terhadap hukum Islam (Othman dan Owen, 2001: 3).

Beberapa indikator syariah compliance (kepatuhan terhadap syari'ah) ini adalah run on Islamic law (menjalankan prinsip-prinsip hukum Islam), provision on Islamic products (sesuai dengan produk Islam), no interest (tidak mengandung riba), dan provision on free interest loans (bebas bunga).

Dimensi syariah compliance ini merupakan kemampuan untuk memenuhi hukum Islam dan beroperasi di bawah prinsipprinsip ekonomi dan perbankan syari'ah. Mahłmu>d Syaltu>t (1966: 12) mendefinisikan syari'ah adalah seperangkat hukum-hukum Allah untuk dipedomani manusia dalam mengatur hubungan dengan Allah, dengan manusia baik sesama muslim atau non muslim, alam dan seluruh kehidupan. Sedangkan Ali as-Sayis (1970: 8; Bakri, 1996: 63) mengartikan syari'ah sebagai hukum-hukum yang diberikan oleh Allah kepada umat manusia agar mereka percaya dan mengamalkannya untuk mendapatkan kebahagiaan di dunia dan akhirat. Definisi di atas menggambarkan syari'ah sebagai seperangkat norma-norma yang mengatur tingkah laku manusia, yang lazim disebut sebagai hukum Islam (Muslim, 2005: 23).

Praja (1995: 113-114) mengemukakan enam asas-asas mu'amalah sebagai berikut: (1) asas saling menguntungkan (taba>du al-mana $>f i$ ); (2) asas pemerataan; (3) saling ridha ('an tara $>$ dlin); (4) bebas manipulasi ('adam al-gara $>$ r); (5) asas al-birr wa attaqwa> dan (6) asas al-musya $>$ rakah. Selain enam asas tersebut di atas, masih dapat dikembangkan menjadi beberapa asas lainnya, yaitu: (1) bebas riba dan eksploitasi (złulm); (2) halal dan tjayyib; (3) tidak memudaratkan ('adam al-mudlarat); (4) larangan spekulasi; dan (5) larangan menimbun/ibltika $>r$ (Muslim, 2005: 54). Sedangkan beberapa basis kebijakan ekonomi Islam, di antaranya adalah sebagai berikut: (1) penghapusan riba; (2) pelembagaan zakat; (3) pelarangan gara $>r$ dan (4) pelarangan yang haram (Misanam, Suseno dan Anto, 2008: 70-72). 


\section{Trust (Kepercayaan)}

Mayer et.al dalam Heijden, Verhagen dan Creemers (2003: 3) mendefinisikan kepercayaan sebagai "the willingness of a party to be vulnerable to the actions of another party based on the expectation that the other will perform a particular action important to the trustor, irrespective of the ability to monitor or control that other party". Moorman dalam Sulaiman, Mohezar dan Rasheed (2007: 193) berpandangan bahwa kepercayaan adalah " a willingness to rely on an exchange partner in whom one has confidence". Senada dengan pendapat tersebut, Morgan dan Hunt dalam Bart et.al. (2005: 4) mengemukakan bahwa kepercayaan merupakan "a willingness to accept vulnerability, but with an expectation or confidence that one can rely on the other party". Sementara itu, Gefen dan Straub (2003: 9) berpandangan bahwa kepercayaan adalah "the belief that other people will react in predictable ways". Beberapa pendapat di atas menggambarkan bahwa kepercayaan akan terjadi apabila seseorang memiliki keyakinan diri kepada reliabilitas dan integritas dari partner.

Berdasarkan beberapa definisi di atas, maka dapat disimpulkan bahwa kepercayaan adalah kesediaan pihak tertentu terhadap pihak lain dalam melakukan hubungan transaksi berdasarkan suatu keyakinan bahwa pihak yang dipercayainya tersebut akan melakukan tindakan sesuai dengan yang diharapkan. Dengan kata lain, kepercayaan itu akan mengukur apakah seseorang mempercayai pihak lain sebagai pihak yang dapat dipercaya.

Beberapa penelitian sebelumnya antara lain; Wahyudi (2011: 44) menunjukkan dalam penelitiannya bahwa perceived expressiveness, perceived enjoyment, perceived ease of use, perceived usefulness dan subjective norm berpengaruh signifikan terhadap minat menggunakan mini laptop. Penelitian Bank Indonesia dan Universitas Brawijaya (2000: 5-20) membagi tiga faktor yang mempengaruhi bank custumer's decision process yaitu: (1) Marketing Stimuli (product, price, promotion dan place); (2) Other Stimuli (economy); dan (3) bank custumer's characteristics (culture, social, personal, psychological). Sedangkan hasil dari uji Logistic Regression menunjukan bahwa faktor-faktor yang mempengaruhi masyarakat individu 
untuk memilih bank syari'ah antara lain adalah: (1) payment periode; (2) warranties; (3) location; (4) economic circumstances; (5) role and status; (6) age and life cycle stages; (7) family dan (8) pendidikan.

Penelitian Bank Indonesia dan Undip tentang potensi, preferensi dan perilaku masyarakat terhadap bank syari'ah di Jawa Tengah dan Daerah Istimewa Yogyakarta (2000: 11) dapat dikemukakan bahwa persepsi masyarakat terhadap bunga bank ternyata cukup bervariasi. Secara umum, sebagian besar masyarakat sebanyak 48,27\% menyatakan bahwa bunga bank adalah haram, masyarakat yang berpendapat bahwa bunga bank adalah halal sebesar 20,47\%, dan masyarakat yang berpandangan bahwa bunga bank adalah subhat adalah 31,47\%. Sementara itu, persepsi masyarakat terhadap produk bank syari'ah menunjukkan bahwa 70,53\% menyatakan mendengar bank syari'ah tetapi belum memahami sistem dan produk bank syari'ah.

Dalam konteks penelitian ini, konsep kepercayaan adalah kepercayaan pada penyelenggaraan transaksi produk bank syari'ah dan kepercayaan pada mekanisme operasional dari transaksi yang dilakukan. Upaya tinggi harus dilakukan oleh penyelenggara transaksi produk bank syari'ah agar kepercayaan konsumen semakin meningkat. Hal ini disebabkan kepercayaan mempunyai pengaruh besar pada niat dan perilaku nasabah untuk menggunakan produk bank syari'ah atau tidak menggunakannya.

Menurut Koufaris dan Hampton-Sosa (2002:15), indikatorindikator trust meliputi: trustworthy, keep the best interest, keep the promises and commitment, believe the information provided dan genuinely concerned. Dengan demikian, jika produk bank syari'ah itu dapat dipercaya oleh para nasabahnya, maka akan mendorong para nasabah untuk menerima dan atau menggunakan produk bank syari'ah tersebut.

Penelitian ini berangkat dari perkembangan bank syari'ah yang cukup pesat, namun tidak diikuti oleh market share-nya sehingga diperlukan suatu analisis dan strategi untuk meningkatkan market share bank syariah dengan menganalisis model adopsi produk-produk bank syari'ah, yang meliputi subjective norm, 
attitude towards use, syariah compliance dan trust. Karenanya, norma subjektif, sikap, kepatuhan syariah dan kepercayaan diprediksi mampu menjelaskan perbedaan perilaku masyarakat terhadap produk bank syari'ah.

Bertitik tolak dari landasan teori dan kerangka pemikiran teoritis tersebut di atas, maka model penelitian dalam penelitian ini adalah:

Gambar 2. Model Penelitian

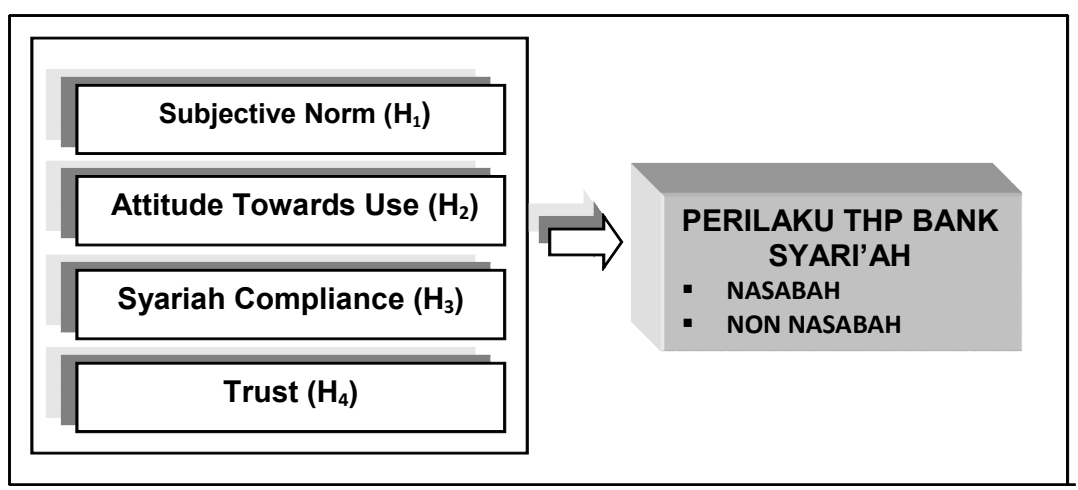

\section{Hipotesis}

Terdapat perbedaan perilaku masyarakat terhadap produk bank syari'ah antara nasabah (adopter) dan non nasabah (non adopter) dipengaruhi oleh subjective norm, attitude towards use, syariah compliance dan trust.

\section{Metode Penelitian}

Penelitian ini merupakan jenis penelitian survey, yaitu penelitian yang dilakukan dengan mengambil sampel secara langsung dari populasi, sehingga ditemukan hubungan-hubungan antar variabel (Sugiyono, 2004: 7). Instrumen penelitian menggunakan 4 (empat) variabel prediktor, yaitu subjective norm, attitude towards use, syariab compliance dan trust, yang bersumber dari Theory of Reasoned Action (TRA) dengan penambahan variabel yaitu syariah compliance dan trust. Sementara itu, kisi-kisi instrumen penelitian adalah sebagai berikut: 
Tabel 2. Kisi-Kisi Instrumen Penelitian

\begin{tabular}{clcl}
\hline No & \multicolumn{1}{c}{ Variabel } & Item & \multicolumn{1}{c}{ Reference } \\
\hline 1 & Subjective Norm & 4 & Venkatesh, dkk (2003) \\
2 & Attitude toward Use & 4 & Venkatesh, dkk (2003) \\
3 & Syariah Compliance & 4 & Othman \& Owen (2001) \\
4 & Trust & 4 & Koufaris \& Hampton-Sosa (2002) \\
\hline
\end{tabular}

Populasi penelitian ini adalah semua masyarakat di Kabupaten Kudus. Penentuan sampel dalam penelitian ini dilakukan dengan menggunakan teknik convenience sampling. Dalam penelitian ini, peneliti mengambil sampel sebanyak 150 responden. Dari 150 instrumen yang disebar kepada responden, ternyata yang kembali dan terisi dengan baik adalah 140 paket kuesioner (response rate sebesar 93\%) sedang sisanya sebanyak 10 paket kuesioner (7\%) tidak kembali. Sementara teknik analisis datanya menggunakan uji statistik discriminant analysis dengan pengujian signifikasi modelnya menggunakan Chi-square dan Wilks Lambda. Alasan yang mendasari penggunaan alat statistik ini karena penelitian ini menguji variabel-variabel prediktor yang dianalisis pengaruhnya terhadap variabel tingkat adopsi produk bank syari'ah yang bersifat kategorik yaitu nasabah (adopter) dan non nasabah (non adopter). Variabel terikat (dependent variable)-nya berbentuk non-metrik (kategorik) sementara variabel bebas (independent variable)-nya lebih dari satu dan berbentuk metrik (Ghozali, 2005: 9).

\section{Analisis}

Dalam model penelitian ini digunakan alat uji statistik, yaitu Analisis Diskriminan (Discriminant Analysis).

\section{Memilih variabel Diskriminator}

Langkah pertama dalam uji statistik analisis diskriminan adalah menentukan perbedaan independent variable, yaitu norma subyektif (subjective norm), sikap (attitude towards use), kepatuhan syariah (syariah compliance), dan kepercayaan (trust) selaku variabel diskriminan dalam melakukan pembedaan dua kelompok (nasabah dan non-nasabah). Perbedaan rata-rata masing-masing 
independent variable, yaitu subjective norm, attitude towards use, syariah compliance dan trust dapat diketahui dengan menggunakan Wilk's Lambda test statistics. Uji Wilk's Lambda test statistics ini berfungsi untuk menguji apakah ada perbedaan secara signifikan antara kedua kelompok (nasabah dan non-nasabah).

Tabel 3 menunjukkan tentang cara awal untuk mengetahui perbedaan masing-masing independent variable sebagai kandidat variabel diskriminator lewat analisis perbedaan nilai means. Nilai means untuk variabel subjective norm pada non nasabah bank syari'ah sebesar 13.23 sedang pada nasabah bank syari'ah sebesar 14.04. Nilai means untuk variabel attitude towards use pada non nasabah sebesar 14.11 dan pada nasabah sebesar 16.87. Nilai means untuk variabel syariah compliance pada non-nasabah sebesar 14.57 dan pada nasabah bank syari'ah sebesar 16.74. Sementara nilai means untuk variabel trust pada non-nasabah sebesar 13.46 dan pada nasabah bank syari'ah sebesar 15.89.

Tabel 3. Group Statistics

\begin{tabular}{|c|c|c|c|c|c|}
\hline \multirow{2}{*}{\multicolumn{2}{|c|}{ Bank Syariah }} & \multirow{3}{*}{$\frac{\text { Mean }}{13.23}$} & \multirow{3}{*}{$\frac{\text { Std. Deviation }}{1.851}$} & \multicolumn{2}{|c|}{ Valid N (listwise) } \\
\hline & & & & Unweighted & Weighted \\
\hline \multirow{4}{*}{$\begin{array}{c}\text { Non } \\
\text { Nasabah }\end{array}$} & SN & & & 70 & 70.000 \\
\hline & AT & 14.11 & 1.593 & 70 & 70.000 \\
\hline & $\mathrm{COM}$ & 14.57 & 1.938 & 70 & 70.000 \\
\hline & TR & 13.46 & 1.657 & 70 & 70.000 \\
\hline & & & & \multicolumn{2}{|c|}{ Valid N (listwise) } \\
\hline \multicolumn{2}{|c|}{ Bank Syariah } & Mean & Std. Deviation & Unweighted & Weighted \\
\hline \multirow[t]{4}{*}{ Nasabah } & SN & 14.04 & 2.170 & 70 & 70.000 \\
\hline & AT & 16.87 & 1.888 & 70 & 70.000 \\
\hline & $\mathrm{COM}$ & 16.74 & 1.961 & 70 & 70.000 \\
\hline & TR & 15.89 & 1.997 & 70 & 70.000 \\
\hline \multirow[t]{4}{*}{ Total } & SN & 13.64 & 2.050 & 140 & 140.000 \\
\hline & $\mathrm{AT}$ & 15.49 & 2.223 & 140 & 140.000 \\
\hline & $\mathrm{COM}$ & 15.66 & 2.227 & 140 & 140.000 \\
\hline & TR & 14.67 & 2.197 & 140 & 140.000 \\
\hline
\end{tabular}

Sumber: data primer diolah, 2012. 
Langkah selanjutnya untuk menentukan variabel diskriminan adalah dengan melihat nilai Wilk's Lambda yang dikonversikan dengan F ratio. Tabel 4 mendeskripsikan hasil uji statistik analisis diskriminan, dimana menunjukkan nilai Wilk's Lambda untuk variabel subjective norm sebesar 0.960 dengan F ratio sebesar 5.707 dan nilai p value (sig) sebesar 0.018. Nilai Wilk's Lambda untuk variabel attitude towards use sebesar 0.613 dengan $F$ ratio sebesar 87.228 dan nilai p value (sig) sebesar 0.000. Nilai Wilk's Lambda untuk variabel syariab compliance sebesar 0.761 dengan $F$ ratio sebesar 43.419 dan nilai $p$ value (sig) sebesar 0.000. Dan terakhir nilai Wilk's Lambda untuk variabel trust sebesar 0.692 dengan $F$ ratio sebesar 61.334 dan nilai $\mathrm{p}$ value (sig) sebesar 0.000. Dengan menggunakan tingkat alpha sebesar 0.05, maka dapat dikatakan bahwa keempat independent variable tersebut, yaitu subjective norm, attitude towards use, syariah compliance dan trust mampu menjadi variabel diskriminan (Lihat tabel 4).

Tabel 4. Tests of Equality of Group Means

\begin{tabular}{lccccc}
\hline & Wilks' Lambda & $\mathrm{F}$ & $\mathrm{df1}$ & $\mathrm{df2}$ & Sig. \\
\hline SN & .960 & 5.707 & 1 & 138 & .018 \\
AT & .613 & 87.228 & 1 & 138 & .000 \\
COM & .761 & 43.419 & 1 & 138 & .000 \\
TR & .692 & 61.334 & 1 & 138 & .000 \\
\hline
\end{tabular}

Sumber: data primer diolah, 2012.

Setelah diketahui variabel diskriminator tersebut di atas, selanjutnya dapat disusun hasil model baru yang dapat digunakan untuk memprediksi kemampuan menjelaskan perbedaan kedua kelompok. Untuk dapat menyusun model baru, maka digunakan hasil perhitungan canonical discriminant function coefficients. 
Tabel 5. Canonical Discriminant Function Coefficients

\begin{tabular}{lr}
\hline & Function 1 \\
\hline SN & -.068 \\
AT & .366 \\
COM & .296 \\
TR & .279 \\
(Constant) & -13.467 \\
\hline
\end{tabular}

Sumber: data primer diolah, 2012.

Dengan mendasarkan pada hasil perhitungan canonical discriminant function coefficients sebagaimana termuat dalam tabel 5, maka dapat dirumuskan model diskriminan yang baru, yaitu:

$$
Z=-13.467-0.068 \mathrm{SN}+0.366 \mathrm{AT}+0.296 \mathrm{COM}+0.279 \mathrm{TR}
$$

\section{Menguji Signifikansi Fungsi (Model) Diskriminan}

Untuk menguji signifikansi statistik dari fungsi diskriminan digunakan multivariate test of significance. Oleh karena dalam kasus ini lebih dari satu variabel diskriminan yaitu subjective norm, attitude towards use, syariah compliance dan trust, maka untuk menguji perbedaan kedua kelompok (nasabah dan non-nasabah) secara bersama-sama digunakan multivariate test.

Uji multivariate ini berupa uji Wilk's Lambda yang diaproximasi dengan statistic Chi-Square. Tabel 6 ini menjelaskan signifikansi variabel diskriminan dalam menjelaskan perbedaan perilaku tingkat adopsi produk bank syari'ah antara nasabah (adopter) dan nonnasabah (non adopter). Dalam tabel 6 menunjukkan bahwa nilai Wilk's Lambda sebesar 0.433 dan Chi Square sebesar 113.890 dengan nilai signifikansi 0.000 , maka dapat disimpulkan bahwa fungsi diskriminan signifikan secara statistik yang berarti nilai means (ratarata) score diskriminan untuk kedua kelompok (nasabah dan nonnasabah) berbeda secara signifikan. Hasil perhitungan ini menunjukkan bahwa secara bersama-sama variabel diskriminan, yaitu subjec- 
tive norm, attitude towards use, syariah compliance, dan trust dapat menjelaskan perbedaan perilaku tingkat adopsi produk bank syari'ah antara nasabah (adopter) dan non-nasabah (non adopter).

Tabel 6. Wilks' Lambda

\begin{tabular}{lcccc}
\hline Test of Function(s) & Wilks' Lambda & Chi-square & df & Sig. \\
\hline 1 & .433 & 113.890 & 4 & .000 \\
\hline
\end{tabular}

Sumber: data primer diolah, 2012.

Untuk mempertegas hasil tersebut di atas, yaitu untuk menguji seberapa besar dan berarti pembedaan antara kedua kelompok (nasabah dan non-nasabah) tersebut, maka dapat dilihat dari hasil perhitungan statistic lewat nilai Square Canonical Correlation $\left(C R^{2}\right)$. Square Canonical Correlation $\left(C R^{2}\right)$ ini identik dengan koeffisien determinan $\left(R^{2}\right)$ pada model regresi yaitu mengukur variasi antara kedua kelompok (nasabah dan non-nasabah) yang dapat dijelaskan oleh variabel diskriminannya. Jadi $\mathrm{CR}^{2}$ mengukur sebarapa kuat fungsi diskriminan.

Tabel 7. Eigenvalues

\begin{tabular}{lrrrr}
\hline Function & Eigenvalue & $\%$ of Variance & Cumulative \% & $\begin{array}{c}\text { Canonical } \\
\text { Correlation }\end{array}$ \\
\hline 1 & $1.310^{\mathrm{a}}$ & 100.0 & 100.0 & .753 \\
\hline
\end{tabular}

Sumber: data primer diolah, 2012.

Tabel di atas memberikan informasi bahwa nilai Canonical Correlation sebesar 0.753 . Kalau nilai korelasi kanonikal ini dikuadratkan $(0.753)^{2}=0.567$. Hal ini memiliki makna bahwa seluruh variabel diskriminan, yaitu subjective norm, attitude towards use, syariab compliance dan trust mampu menjelaskan perbedaan perilaku tingkat adopsi produk bank syari'ah antara nasabah (adopter) dan non-nasabah (non adopter) sebesar 56.7\% atau dengan kata lain, 56.7\% variasi antara kelompok nasabah (adopter) dan non-nasabah (non adopter) dapat dijelaskan oleh keempat variabel diskriminan. 
3. Menentukan Tingkat Kemampuan Menjelaskan Variabel Diskriminator

Untuk menilai tingkat pentingnya masing-masing variabel diskriminator dan arti dari fungsi diskriminan dapat dilakukan dengan melihat standardized koeffisien fungsi diskriminan (standardized canonical discriminant function coefficient). Hasil dari perhitungan ini ditujukan untuk mengetahui tingkat masingmasing variabel diskriminator mampu menjelaskan perbedaan perilaku tingkat adopsi produk bank syari'ah antara nasabah (adopter) dan non-nasabah (non adopter).

Tabel 8 ini menjelaskan tentang hasil nilai standardized canonical discriminant function yang menunjukkan bahwa variabel attitude towards use memiliki kemampuan menjelaskan fungsi atau model diskriminan paling tinggi yaitu menunjukkan nilai sebesar 0.638 , selanjutnya variabel syariab compliance yang menunjukkan nilai sebesar 0.577 , disusul trust yaitu menunjukkan nilai sebesar 0.512, dan selanjutnya variabel terakhir adalah subjective norm yang menunjukkan nilai sebesar -0.137 .

Tabel 8. Standardized Canonical Discriminant Function

Coefficients

\begin{tabular}{lc}
\hline & Function 1 \\
\hline SN & -.137 \\
AT & .638 \\
COM & .577 \\
TR & .512 \\
\hline
\end{tabular}

Sumber: data primer diolah, 2012.

4. Ketepatan Klasifikasi dari Dua Kelompok

Ketepatan klasifikasi dari dua kelompok (nasabah dan non nasabah) dapat dilihat pada hasil output SPSS yang memberikan nilai tingkat klasifikasi sebesar 95.7\%. Ringkasan hasil klasifikasi dapat dilihat pada tabel classification results yang menjelaskan bahwa 95.7\% dari data telah terklasifikasi dengan benar. Hal ini berarti $95.7 \%$ dari 140 data yang diolah telah dimasukkan pada 
grup yang sesuai dengan data semula. Hasil matrik klasifikasi menunjukkan pula bahwa 134 observasi telah diklasifikasi secara benar dan hanya 6 observasi diklasifikasikan salah. Dengan demikian, ketepatan klasifikasi adalah 134/140 atau 95.7\%.

Tabel 9. Classification Results

\begin{tabular}{lllccc}
\hline & \multirow{2}{*}{ Bank Syariah } & \multicolumn{2}{c}{ Predicted Group Membership } & \multirow{2}{*}{ Total } \\
\cline { 3 - 4 } & & Non Nasabah & Nasabah & \\
\hline Original & Count & Non Nasabah & 69 & 1 & 70 \\
& & Nasabah & 5 & 65 & 70 \\
& $\%$ & Non Nasabah & 98.6 & 1.4 & 100.0 \\
& Nasabah & 7.1 & 92.9 & 100.0 \\
\hline
\end{tabular}

a. $95.7 \%$ of original grouped cases correctly classified.

Sumber: data primer diolah, 2012.

\section{Kesimpulan}

Berdasarkan pengujian yang telah dilakukan terhadap hipotesis yang telah diajukan sebelumnya, menghasilkan beberapa kesimpulan sebagai berikut: 1) subjective norm mampu menjelaskan perilaku masyarakat terhadap produk bank syari'ah antara nasabah (adopter) dan non nasabah (non-adopter); (2) attitude towards use mampu menjelaskan perilaku masyarakat terhadap produk bank syari'ah antara nasabah (adopter) dan non nasabah (non-adopter); (3) syariab compliance mampu menjelaskan perilaku masyarakat terhadap produk bank syari'ah antara nasabah (adopter) dan non nasabah (non-adopter); dan (4) trust mampu menjelaskan perilaku masyarakat terhadap produk bank syari'ah antara nasabah (adopter) dan non nasabah (non-adopter).

Studi ini memiliki beberapa keterbatasan antara lain: (1) hanya terbatas pada perilaku masyarakat di Kabupaten Kudus sehingga perlu pengujian ulang dengan melibatkan obyek penelitian yang lebih luas, dalam penelitian mendatang; (2) hanya terbatas pada responden adalah masyarakat terhadap produk bank syari'ah, baik produk funding maupun financing. Oleh karena itu, sebuah penelitian mendatang diarahkan untuk melakukan pengujian pada 
produk bank syari'ah yang lebih spesifik lainnya; (3) Studi ini menggunakan variabel prediktor dari Theory of Reasoned Action (TRA) yang diintegrasikan dengan syariab compliance dan trust dan (4) Design penelitian ini menggunakan uji discriminant analysis (analisis diskriminan) dengan 2 skala kategorik, yaitu nasabah bank syari'ah dan non nasabah.

\section{Daftar Pustaka}

Bakri, Asafri Jaya. 1996. Konsep Maqashid Syari'ah Menurut AsySyatibi, Jakarta: PT RajaGrafindo Persada.

Bank Indonesia dan PPKP LP Undip Semarang. 2000. Potensi, Preferensi dan Perilaku Masyarakat Terhadap Bank Syari'ah di Wilayah Jawa Tengah dan Daerah Istimewa Yogyakarta. Executive Summary: 1-30.

Bank Indonesia dan Pusat Pengkajian Bisnis dan Ekonomi Islam Fak. Ekonomi UNIBRA. 2000. Potensi, Preferensi dan Perilaku Masyarakat terhadap Bank Syari'ah di Jawa Timur. Executive Summary: 1-22.

Bank Indonesia. 2012. Statistik Perbankan Syari'ah.

Bart, et.al.. 2005. Are The Drivers and Role of Online Trust The Same for All Web Sites and Consumers? A Large Scale Exploratory Empirical Study. Center for e-Business@MIT: 1-34.

Davis, Fred D., Bagozzi, Richard P., dan Warshaw, Paul R.. 1989. User Acceptance of Computer Technology: A Comparison of Two Theoretical Models. Management Science, Vol. 35, No. 8: 982-1003.

Gefen, David, dan Straub, Detmar W.. 2003. Managing User Trust in B2C E-Services. E-Service Journal: 7-24.

Ghozali, Imam. 2005. Aplikasi Multivariate dengan Program SPSS, Semarang: UNDIP.

Heijden, Hans Van der; Verhagen, Tibert dan Creemers, Marcel. 2003. Understanding Online Purchase Intentions: Contributions From Technology and Trust Perspectives. European Journal of Information Systems: 41-48.

Ismail, Rifki, Ascarya dan Sakti, Ali. 2012. Outloook Perbankan Syari'ah 2012. didownload dari http:// 
www.pkesinteraktif.com, diakses 6 Januari 2012.

Koufaris, Marios dan Hampton-Sosa, William. 2002. Customer Trust Online: Examining The Role of The Experience with The Website. CIS Working Paper Series: 1-20.

Lavindri, Edith dan Kurnia, Pepey Riawati. 2012. Analisis FaktorFaktor yang Mempengaruhi Adopsi Twitter Advertising pada Segmen Muda Usia 15-24 Tahun Wilayah Jabodetabek Tahun 2011. Journal of Management and Business Review, Vol. 9, No. 1: 1-14.

Misanam, Munrokhim, Suseno, Priyonggo dan Anto, M. Bhekti Hendrie. 2008. Ekonomi Islam, Jakarta: PT RajaGrafindo Persada.

Muslim, Muslihun. 2005. Fiqh Ekonomi, Mataram: LKIM IAIN Mataram.

Othman, Abdul Qawi dan Owen, Lynn. 2001. The Multi Dimensionality of CARTER Model to Measure Customer Service Quality (SQ) in Islamic Banking Industry: A Study in Kuwait Finance House. International Journal of Islamic Financial Services, Vol. 3, No. 4: 1-12.

Praja, Juhaya S. 1995. Filsafat Hukum Islam, Bandung: LPPM Universitas Islam Bandung.

Reid, Michael dan Levy, Yair. 2008. Integrating Trust and Computer Self-Efficacy with TAM: An Empirical Assessment of Customers' Acceptance of Banking Information System (BIS) in Jamaica. Journal of Internet Banking and Commerce, Vol.13, No.3: 118.

Saragih, Nawary. 2010. Aplikasi Theory of Reasoned Action untuk Memprediksi Minat Dominan Membeli Sepeda Motor Yamaha Mio pada Masyarakat Kecamatan Medan Petisah. Media Unika, Vol. 3, No.72: 362-381..

Sayis, as-, Ali. 1970. Nasy'ah al-Fiqh al-Ijtiha $>>$ di wa Atłwa $>$ ruh, Kairo: Majma' al-Buhus al-Islamiyyah.

Sugiyono. 2004. Metode Penelitian Bisnis, Bandung: Alfabeta.

Sulaiman, Ainin, Mohezar, Suhana, dan Rasheed, Ahmad. 2007. A

Trust Model for E-Commerce in Pakistan: An Empirical Research. Asian Journal of Information Technology, Vol. 6, 
No.2: 192-199.

Syaltu>t, Mahłmu>d. 1966. Al-Isla>>m: 'Aqi>dah wa Syari> ah, Kairo: Dar al-Qalam.

Vallerand, Robert J. dan Pelletier, Luc G.. 1992. Ajzen and Fishbein's Theory of Reasoned Action as Applied to Moral Behavior: A Confirmatory Analysis. Journal of Personality and Social Psychology, Vol. 62, No. 1: 98-109.

Wahyudi, Handri Dian. 2011. Analisis Sikap dan Niat Menggunakan Mini Laptop: Studi Pengembangan Model Penerimaan Teknologi. Jurnal Ekonomi Bisnis, Vol. 16, No.1: 44-52.

Winarto. 2008. Pengaruh Sikap dan Norma Subyektif terhadap Minat dan Keputusan Memilih Kuliah di Universitas Hang Tuah Surabaya. Aplikasi Administrasi, Vol. 10, No. 1: 51-64. 